Artigo

\title{
Pedras no Caminho da Adoção Tardia: Desafios para o Vínculo Parento-Filial na Percepção dos Pais
}

\author{
Débora da Silva Sampaio* \\ orcid.org/0000-0001-5697-0856 \\ Andrea Seixas Magalhães \\ orcid.org/0000-0003-2992-9844 \\ Terezinha Féres-Carneiro \\ orcid.org/0000-0002-0564-7810
}

Pontifícia Universidade Católica do Rio de Janeiro, Rio de Janeiro, RJ, Brasil

\begin{abstract}
Resumo
O presente artigo é parte de pesquisa mais ampla sobre o vínculo parento-filial nas adoções tardias. Foram entrevistados 10 sujeitos independentes, 3 homens e 7 mulheres, que adotaram crianças maiores de dois anos e as entrevistas analisadas pelo método de análise de conteúdo. O objetivo deste estudo foi investigar a vivência do período de adaptação nas adoções tardias e a repercussão do histórico pregresso da criança na construção do vínculo parento-filial. Dentre as principais dificuldades relatadas durante esse período, ressaltam-se o comportamento agressivo da criança, as dificuldades com regras e autoridade, a falta de segurança jurídica, o atraso escolar e problemas quanto à adaptação à rotina familiar, todas relacionadas às vivências passadas para a criança. A forma como os pais acolheram as dificuldades, integrando passado e presente, de modo a reconstruir o ambiente familiar perdido, foi relatada como de extrema importância para a construção e manutenção do vínculo parento-filial.
\end{abstract}

Palavras-chave: Adoção tardia, vínculo, parentalidade.

\section{Teething Problems in Late Adoption: Challenges for the Parent-Child Bond in Parental Perception}

\begin{abstract}
This article is part of a broader research on the parent-child bond in late adoption. The authors interviewed ten independent subjects - three men and seven women, who adopted children older than two years - and assessed the results using the content analysis method. The purpose of this study was to investigate the experience of the adaptation period in late adoption, and the repercussions of the previous child history the construction of the parent-child bond. Among the main challenges reported during this period, the authors highlight the aggressive behavior of the child; trouble dealing with rules and authority; lack of legal security; school delays; and problems adapting to family routine, all of which seem
\end{abstract}

* Endereço para correspondência: Pontifícia Universidade Católica do Rio de Janeiro, Centro de Teologia e Ciências Humanas, Departamento de Psicologia, Rua Marquês de São Vicente, 225, Gávea, Rio de Janeiro, RJ, Brasil 22453-900. E-mail: deborasampaio@rocketmail.com, andreasm@puc-rio.br e teferca@puc-rio.br Apoio: Coordenação de Aperfeiçoamento de Pessoal de Nível Superior (Capes). 
to be related to the previous experiences of the child. The way in which parents embraced hardships, bridging past and present in order to rebuild the lost family environment, was reported as having critical importance in the construction and maintenance of the parent-child bond.

Keywords: Late adoption, bond, parenting.

\section{Piedras en el Camino de la Adopción Tardía: Retos para el Vínculo Parento-Filial en la Percepción de los Padres}

\section{Resumen}

El presente artículo es parte de una investigación más amplia sobre el vínculo parento-filial en las adopciones tardías. Fueron entrevistados 10 sujetos independientes, 3 hombres y 7 mujeres, que adoptaron niños mayores de dos años. Las entrevistas fueron analizadas por el método de análisis de contenido. El objetivo de este estudio fue investigar la vivencia del periodo de adaptación en las adopciones tardías y la repercusión del histórico anterior del niño en la construcción del vínculo parento-filial. Entre las principales dificultades relatadas durante este período, resaltamos el comportamiento agresivo del niño; dificultades con reglas y autoridad; falta de seguridad jurídica; retraso en la enseñanza; y problemas de adaptación a la rutina familiar, todas estas relacionadas con las vivencias pasadas del niño. La forma como los padres acogieron las dificultades, integrando el pasado con el presente, como un modo de reconstruir el ambiente perdido, fue relatada como de extrema importancia para la construcción y mantenimiento del vínculo parento-filial.

Palabras clave: Adopción tardía, vínculo, parentalidad.

No Brasil, muitas crianças e adolescentes passam parte de suas vidas em instituição de acolhimento. Algumas delas aguardam a reinserção no seio familiar de origem, enquanto outras compõem a lista para adoção. De acordo com o Estatuto da Criança e do Adolescente (ECA), o tempo de acolhimento de uma criança em instituição deve ser transitório, priorizando o convívio familiar (Lei n. 8.069, 1990). Em 2009, após 19 anos, o ECA (Lei no 8.069/90) sofreu sua primeira reforma. A Lei Nacional de Adoção (Lei n. 12.010, 2009) alterou 54 artigos da primeira Lei, além de promover algumas inovações.

De acordo com essa lei, as instituições de acolhimento ficam responsáveis por adotarem o princípio da preservação dos vínculos familiares e da promoção da reintegração familiar. Desta forma, nota-se que a nova lei tem como principal prerrogativa auxiliar as famílias visando promover o restabelecimento do convívio familiar o mais breve possível (Silva \& Arpini, 2013). Contudo, essa ainda é uma realidade que não foi alcançada. As crianças permanecem por muito tempo nos abrigos, tornando a possibilidade de adoção cada vez mais difícil.

Em muitos casos, devido à demora na tentativa de reinserção familiar, o processo de destituição do poder familiar da família de origem se faz muito longo e, por isso, a criança fica disponível para adoção já com a idade mais avançada. Diante desse quadro, a maioria das crianças que compõem a lista de espera são maiores de dois anos, configurando as chamadas "adoções tardias" (Vargas, 1998/2013).

Apesar de não haver distinções entre as formas de adoção no âmbito jurídico, existe a separação de tipos de adoção, já que algumas requerem atenção especial por serem consideradas especialmente difíceis. Dentre estas, encontram-se as adoções de grupos de irmãos, de crianças HIV positivo, adoções inter-raciais, de crianças com necessidades especiais e a adoção tardia (Peiter, 2011). No caso das adoções tardias, a própria nomeação particular aponta para existência de singularidades e especificidades, dentre as quais, o histórico de vivências anteriores, as difi- 
culdades no período de adaptação e a prerrogativa de escolha da criança.

Segundo Ebrahim (2001), o perfil das crianças maiores, geralmente, não se enquadra na preferência da maioria dos pretendentes à adoção. Por isso, acaba sendo a opção, na maioria dos casos, de casais que já passaram pela experiência parental, de solteiros, de indivíduos divorciados e viúvos que não possuem disponibilidade ou desejo de cuidar de um recém-nascido. Frequentemente, a justificativa para preferência por bebês aparece relacionada com a dificuldade na educação de uma criança maior e com a busca por melhor adaptação entre pais e filhos sem interferência de aprendizados anteriores. Trata-se de uma tentativa de amenizar as consequências de vivências que a criança possa trazer consigo, satisfazendo, assim, o anseio da família de reproduzir um modelo biológico (Morelli, Scorsolini-Comin, \& Santeiro, 2015).

A consequência da distorção entre preferência e perfil disponível aparece na disparidade dos números estatísticos contidos em relatórios do Cadastro Nacional de Adoção (CNA). No ano de 2016, são 35770 pretendentes disponíveis aguardando pela chegada de um filho, enquanto existem 4943 crianças e adolescentes disponíveis para adoção (CNA, 2016).

Nos últimos 20 anos, muitos avanços foram alcançados por meio da conscientização dos pretendentes sobre o perfil da criança, sobretudo devido ao trabalho realizado nos Grupos de Apoio à Adoção, organizações sem fins lucrativos, coordenadas, comumente, por pais adotivos, militantes do movimento a favor de uma nova cultura da adoção. Amim e Menandro (2007) destacam que o trabalho realizado nesses grupos auxilia na mudança do perfil escolhido inicialmente durante o cadastro. Segundo os autores, apenas 4\% dos pretendentes chegam ao grupo dispostos a adotarem crianças maiores de quatro anos e, ao final dos encontros, esse número já chega a $20 \%$.

Apesar das transformações ocorridas até aqui, construir uma nova cultura da adoção no Brasil que quebre antigos mitos e preconceitos é uma tarefa que ainda impõe muitos desafios. A adoção se apresenta como principal solução para tentar reconstruir um ambiente familiar que se adeque às necessidades da criança com um histórico de perdas e separações. A literatura tem mostrado que o processo de adoção tardia envolve diversas especificidades e desafios tanto para os pais quanto para as crianças, sobretudo, no que diz respeito ao período inicial de convivência (Ghirardi, 2009; Levinzon, 2000; Levy, Pinho, \& Faria, 2009; Peiter, 2011).

O histórico de convivências complexas com a família de origem, vizinhos ou conhecidos, além da passagem por instituições de acolhimento são as principais especificidades da adoção tardia (Peiter, 2011). Assim, pode-se dizer que a construção do vínculo parento-filial será permeada pelas vivências anteriores, tanto dos pais quanto das crianças, num processo que demanda construção de ambas as partes, considerando que a criança, muitas vezes, já é capaz de discernir o que deseja e compreender a adoção.

$\mathrm{O}$ rompimento de vínculos familiares em tempo precoce pode deixar marcas para o desenvolvimento da criança. A ida para família adotiva aparece como um momento de ressignificação de experiências de separações anteriores. Além disso, de acordo com Londen, Juffer e Ijzendoorn (2007), a adoção representa papel importante para o desenvolvimento e pode impedir atrasos no desenvolvimento cognitivo e motor da criança.

A adoção pode ser entendida como a possibilidade de reinvestir em objetos que outrora foram ameaçados devido a experiências de ruptura de vínculo. Todavia, é importante destacar que a adoção não pode ser vivida como uma solução mágica para todos os problemas. Peiter (2011) salienta que essa não é uma alternativa que, por si só, seja capaz de ultrapassar os traumas que possam haver na trajetória dessas crianças.

As vivências anteriores podem ter deixado marcas e traumas que influenciariam as vinculações futuras. Para Winnicott (1945/2000a), as experiências vividas como trauma, inicialmente, são experienciadas no corpo, não tendo representação psíquica. Essas e outras experiências vão se acumulando no histórico dessas crianças desde o rompimento com a família biológica, incluindo a passagem por instituições de acolhimento, até a chegada à família adotiva. 
Compreender esse percurso pode ajudar os pais a lidarem com as possíveis dificuldades que se apresentarão durante a adaptação (Morelli et al., 2015; Schettini, Amazonas, \& Dias, 2006; Silva, Guimarães, \& Pereira, 2014).

A chegada numa família adotiva será perpassada pelas histórias, marcas e possíveis traumas experienciados pela criança que, muitas vezes, é exposta a situações de risco registradas no aparelho psíquico como, por exemplo, descuido e desapego, e isto pode gerar dificuldades em criar novos vínculos (Zornig \& Levy, 2006). Nesse contexto, ao abordar o tema de adoção de crianças maiores, a reflexão sobre o histórico e experiências anteriores à adoção se mostra fundamental para compreender a construção do novo vínculo parento-filial. Portanto, é na demanda de reconstruir um ambiente suficientemente bom, além da busca por satisfazer as próprias motivações para uma adoção, que as famílias adotantes encontrarão desafios importantes na construção do vínculo (Gomes, 2006; Otuka, Scorsolini-Comin, \& Santos, 2012).

Diversas pesquisas apontam para a importância de legitimar o passado da criança, dando espaço para que o histórico possa ser recontado e não ocupe o espaço de fantasma na relação familiar (Ebrahim, 2001; Ladvocat, 2001; Levinzon, 2000; Schettini et al., 2006; Silva et al., 2014; Zornig \& Levy, 2006). Ladvocat (2001), ao falar sobre os mitos que envolvem as famílias adotivas, destaca que o desconhecimento acerca da história das origens da criança, na maioria dos casos, acaba favorecendo o surgimento de mitos difundidos pela cultura. Alguns pais preferem apagar a vida anterior do seu filho na tentativa de construir uma nova, sobretudo pela busca de reprodução do modelo biológico de família. Contudo, o acesso ao passado se faz fundamental para que a criança possa fantasiar, perguntar e elaborar junto à família adotiva sua história. É necessário que os pais adotivos compreendam que "ser pai/mãe" é mais importante do que gerar um filho.

De acordo com Schettini et al. (2006), o histórico da criança adotada representa parte da sua identidade e não pode ser anulado, antes, deve ser integrado à nova ligação afetiva. Ressignifi- car o passado fará parte do processo de construção da identidade da criança. Para os autores, o que se entende por revelação da história perde sentido na medida em que não existe revelação, mas uma história que é vivida e construída no dia a dia. Diante desse contexto, este estudo teve por objetivo investigar a vivência do período de adaptação nas adoções tardias e a repercussão do histórico pregresso da criança na construção do vínculo parento-filial.

\section{Método}

\section{Participantes}

Foram entrevistados 10 sujeitos independentes, 3 homens e 7 mulheres, pertencentes a 3 famílias monoparentais, 3 homoparentais e 4 heteroparentais, com escolaridade superior, que estão com guarda provisória ou com processo de adoção concluído. No caso dos pais com guarda provisória, a destituição do poder familiar pode, ou não, ter sido concluída, embora as crianças estejam em processo adoção. Esse tipo de situação ocorre, frequentemente, no estado do Rio de Janeiro. As crianças foram acolhidas pelas famílias com idades que variaram entre dois anos e seis meses e 11 anos, configurando a chamada adoção tardia, anterior ao período da adolescência. Além disso, o processo de adoção, com a guarda provisória, teve início há, no mínimo, seis meses, antes da realização da pesquisa.

\section{Instrumento}

Como instrumento de investigação, realizou-se uma entrevista individual com roteiro semiestruturado, contendo questões abertas, composta pelos seguintes eixos temáticos: motivação para a adoção; vivências anteriores, familiares e rede; experiências subjetivas da parentalidade, experiência da construção do vínculo, fantasias relacionadas ao filho imaginado.

\section{Procedimentos}

Após aprovação do projeto de pesquisa pelo Comitê de Ética em Pesquisa da universidade onde foi desenvolvido, os participantes foram recrutados a partir do contato com os Grupos de apoio 
Tabela 1

Dados Biográficos dos Participantes

\begin{tabular}{|c|c|c|c|c|c|c|c|}
\hline Participante & Idade & Profissão & $\begin{array}{l}\text { Configuração } \\
\text { familiar }\end{array}$ & $\begin{array}{l}\text { Idade da criança } \\
\text { quando adotada }\end{array}$ & $\begin{array}{l}\text { Idade atual } \\
\text { da criança }\end{array}$ & $\begin{array}{l}\text { Processo } \\
\text { concluído }\end{array}$ & $\begin{array}{l}\text { Filhos } \\
\text { biológicos }\end{array}$ \\
\hline Ana & 35 & Advogada & Heteroparental & $\begin{array}{l}\text { 2a; 3a 6m } \\
\text { (irmãos) }\end{array}$ & $4 a ; 5 a 6 m$ & - & - \\
\hline André & 47 & $\begin{array}{l}\text { Engenheiro } \\
\text { civil }\end{array}$ & Monoparental & $11 \mathrm{a}$ & $15 \mathrm{a}$ & Sim & - \\
\hline Mario & 39 & Contador & Homoparental & $\begin{array}{c}\text { 11; } 2 \mathrm{a} 6 \mathrm{~m}, 1 \mathrm{a} 6 \mathrm{~m} ; \\
3 \mathrm{~m} \text { (irmãos) }\end{array}$ & $\begin{array}{c}13 \mathrm{a} ; 5 \mathrm{a} ; 3 \mathrm{a} ; \\
2 \mathrm{a}\end{array}$ & Sim & - \\
\hline Claudia & 50 & Professora & Heteroparental & $\begin{array}{c}\text { 6a; 8a } \\
\text { (irmãos) }\end{array}$ & $7 a ; 8 a$ & - & - \\
\hline Lucas & 38 & Projetista & Homoparental & $\begin{array}{l}\text { 6a; 9a; 11a } \\
\text { (irmãos) }\end{array}$ & $7 \mathrm{a} ; 10 \mathrm{a} ; 11 \mathrm{a}$ & - & - \\
\hline Sara & 44 & Contadora & Heteroparental & $7 \mathrm{a}$ & $10 \mathrm{a}$ & - & - \\
\hline Fernanda & 45 & $\begin{array}{c}\text { Professora } \\
\text { universitária }\end{array}$ & Heteroparental & $\begin{array}{l}4 \mathrm{a} ; 10 \mathrm{a} \\
\text { (irmãos) }\end{array}$ & $5 a ; 11 a$ & - & Sim \\
\hline Julia & 37 & $\begin{array}{l}\text { Consultora } \\
\text { de beleza }\end{array}$ & Monoparental & $2 \mathrm{a} 6 \mathrm{~m}$ & $6 a$ & Sim & - \\
\hline Vânia & 45 & Advogada & Homoparental & $6 \mathrm{~m}, 5 \mathrm{a} ; 12 \mathrm{a}$ & $27 \mathrm{a} ; 12 \mathrm{a} ; 16 \mathrm{a}$ & Sim & - \\
\hline Laura & 46 & $\begin{array}{l}\text { Assistente } \\
\text { social }\end{array}$ & Monoparental & $9 a$ & $15 \mathrm{a}$ & Sim & Sim \\
\hline
\end{tabular}

à Adoção e, também, por contatos informais em diferentes redes sociais da pesquisadora. As entrevistas foram realizadas em local de preferência do entrevistado, gravadas em áudio, com a devida autorização dos participantes, mediante a assinatura de um Termo de Consentimento Livre e Esclarecido e tiveram duração média de uma hora. Os nomes dos pais utilizados ao longo do trabalho foram devidamente substituídos por nomes fictícios.

O material foi transcrito e submetido ao método de análise de conteúdo, na sua vertente categorial, com a finalidade de investigar, a partir do material discursivo, as significações atribuídas pelas entrevistadas aos fenômenos (Bardin, 2011). Por meio da técnica categorial, foram destacadas categorias temáticas, organizadas a partir da semelhança entre os elementos contidos no material coletado. Para tal, procedeu-se a uma "leitura flutuante", agrupando-se dados significativos, identificando-os e relacionando-os, até se destacarem as categorias de análise.

O presente trabalho apresenta parte dos resultados de pesquisa ampla, cujo objetivo foi investigar a construção do vínculo parento-filial nas adoções tardias. Nessa pesquisa mais ampla, emergiram sete categorias das narrativas dos participantes: vivência da parentalidade, motivação para adoção, participação da rede, fantasias e expectativas na adoção tardia, bagagem da criança, pedras no caminho da adoção tardia e adoção mútua.

Para alcançar os objetivos deste trabalho, foram discutidas as três últimas categorias, por estarem diretamente relacionadas às implicações do histórico na construção mútua do vínculo parento-filial da adoção. As outras categorias foram discutidas em outro trabalho. 


\section{Resultados e Discussão}

\section{Bagagem da Criança}

Os entrevistados relataram receio diante dos costumes e aprendizados adquiridos no passado da criança, sendo essa uma das principais dificuldades iniciais na construção do vínculo parento-filial.

Digamos, ela chegou com onze anos, já chegou com uma bagagem. Como que a gente vai desconstruir, explicar isso pra ela? As vezes até repreendê-la, mas sem fazer com que ela retorne lá atrás pra falar "ah! Mas antes isso comigo não acontecia". (Mario, família homoparental)

Segundo Vargas (1998/2013), apesar de a educação ser tão importante quanto a natureza biológica, o temor da herança patológica é um assunto frequentemente abordado por pais adotivos. Assim, prevalece a ideia de que, não importa o que se faça, a personalidade da criança sempre será modelada pela "semente ruim" proveniente do biológico. Luz, Gelani e Amaral (2014) apontam para a importância dessa desmistificação, uma vez que a crença de que a criança virá com maus hábitos pode comprometer tanto a construção do vínculo quanto o próprio desenvolvimento futuro da criança.

Para a maioria dos entrevistados, os medos a respeito do que a criança traz consigo, foram sendo desconstruídos durante o processo da adoção.

Quando a gente entrou no processo de adoção, a gente tinha colocado de zero a seis anos, um só, mas eu descobri que esse perfil não era muito baseado em desejo. Ele era baseado em medo e em um bando de fantasias. Então conforme a gente foi fazendo as palestras e eu fui conversando com as pessoas, eu fui ficando mais seguro com relação a isso. (Lucas, família homoparental)

Nas falas de alguns pais, pode-se notar o receio de que o preconceito e os estigmas provenientes da educação recebida prejudicassem o vínculo parento-filial. Para Mario, a aceitação ou não da homossexualidade foi uma das preocupações ao decidir adotar.
E outra grande preocupação era a questão do gênero, no início a gente ficou meio assim porque achava que como era um casal gay, a facilidade seria menina, né. Porque a menina lidaria muito melhor com a questão nossa da homossexualidade e o menino já carregaria aquela bagagem preconceituosa do local de onde veio, que geralmente são lugares mais carentes, mais pobres, e como isso seria? (Mario, família homoparental)

Segundo Fernández e Fuentes (2004), nos países ocidentais, tratando-se de adoção de crianças maiores, nota-se preferência pela adoção de meninas. Isso se deve a aspectos psicológicos da escolha, como, por exemplo, a busca de afeto e apoio, além de aspectos sociais e culturais, como a valorização da atração estética, da obediência e da submissão atribuídas ao gênero feminino.

A dificuldade com os cuidados básicos de higiene apareceu nas falas de alguns dos entrevistados como uma das dificuldades relacionadas ao histórico marcado por negligências.

Então a gente tem que iniciar uma nova educação, literalmente. Apesar deles terem dez e quatro era como se fossem bebês. Escovar dentes, tomar banho todos os dias, então, coisa de histórico, escovar dente, tomar banho . . . Teve uma reeducação total praticamente devido ao histórico deles que era um histórico de crianças largadas. (Fernanda, família heteroparental)

A rotina nas instituições de acolhimento, muitas vezes, não favorece o aprendizado de cuidados essenciais. A predominância da função assistencialista, somada à falta de estrutura dessas instituições, fragiliza o compromisso voltado ao desenvolvimento da infância e da adolescência. Essas instituições não conseguem abarcar toda a demanda de cuidados necessários às crianças devido a inúmeros fatores como, por exemplo, número reduzido de funcionários, alta rotatividade, sobrecarga de funções, salários desfavoráveis e falta de especialização (Altoé \& Silva, 2013).

Baptista, Soares e Henriques (2013) destacam que a impossibilidade de oferecer a satisfação dos cuidados básicos nas instituições está relacionada à baixa capacidade em alcançar as 
necessidades individuais das crianças. O reduzido número de cuidadores e as mudanças constantes nos turnos impossibilitam a existência de certa estabilidade desses profissionais e desfavorecem a promoção de atividades para o desenvolvimento dessas crianças. Esses fatores acabam prejudicando o estabelecimento de figuras de referência, podendo fragilizar a capacidade de vinculação futura com a família adotiva.

Toda essa negligência sofrida no passado pode ter consequências importantes para o desenvolvimento. Alguns pais destacaram defasagens no desenvolvimento como parte do histórico dos seus filhos.

Ela vivia presa em algum lugar, porque ela com um ano e meio, ela não andava, ela não engatinhava, ela não falava ... Então com dois meses ela já tava correndo. Ai o pessoal do abrigo falava assim: "ela não anda, só corre”. Ai você, é claro, né! perdeu muito tempo sem fazer nada, tem que botar o tempo em dia. (Julia, família monoparental) Bôing e Crepaldi (2004) assinalam que observações em hospitais, creches, abrigos nos quais a privação, por vezes, é maciça, mostram que os danos no desenvolvimento psicoafetivo aparecem de forma grave, no que seria denominado de "hospitalismo". Além disso, quando a privação é severa, pode ocorrer dificuldade na capacidade da criança de estabelecer vínculos futuros.

A defasagem advinda da falta de cuidados iniciais emergiu nas falas dos entrevistados sobre a dificuldade com a adaptação da rotina familiar.

A dificuldade foi essa parte da adoção mesmo porque eles reagiram de uma forma que cada um reage de uma forma, que nem a da B que chorava muito, né, o L que falava só sim, então a dificuldade foi tentar entrar no meio termo, colocá-los num ponto, alinhá-los de acordo com a rotina da família. (Fernanda, família heteroparental)

A necessidade de cuidados para reparar o que antes foi negligenciado requer transformações de rotinas. Conforme Luz et al. (2014), a rotina se apresenta como questão importante na adaptação, tanto para a família que irá receber um novo membro, quanto para a criança que, por conta do seu histórico, pode não aceitar tão bem a imposição de novas regras. A falta de informação sobre o histórico da criança também foi mencionada, sobretudo na fala de Sara, ao contar sobre seu desespero ao se deparar com o filho doente.

E eu não sabia nada, nada, nada, nada. Eu falei, "olha doutora, eu só sei o tipo sanguíneo dele porque me deram no abrigo, o resto eu não sei nada, nada, não sei histórico dele nenhum, a senhora, por favor, me ajuda que essa criança fica com secreção o tempo todo, e eu não sei o que eu faço". (Sara, família heteroparental)

Gomes (2008) assinala que, na maioria das vezes, a família adotiva não tem acesso a informações essenciais sobre o início de vida da criança como as condições do parto, histórico de doenças comuns na infância, aspectos relevantes do avanço no desenvolvimento, dentre outros. Diante disso, terá que oferecer cuidados específicos à adoção para conseguir reparar as falhas anteriores.

A insegurança da criança foi reconhecida por alguns entrevistados como uma das consequências da história pregressa dos seus filhos. Perceber isto ajudou a moldar o cuidado necessário para que a segurança fosse reestabelecida.

Nossa primeira, vamos dizer assim, não foi briga, nossa primeira bronca mais séria, né, com a minha cara mais séria, ela na hora disse assim: "você vai me abandonar?" . . . Eu nunca falei quando ela fazia alguma pirraça na rua, igual mãe faz, assim: "não vai vir não? Então vou embora!" Nunca falei isso, podia tá o que fosse. . . . Mas na rua, falar: "oh, to indo embora e você vai ficar aí", nunca falei, porque vai trazer um sofrimento que já é, na verdade, pra qualquer criança, né, a mãe falar que vai embora, pra qualquer criança já é um sofrimento. Mas pra elas é maior ainda, porque já foram né, outros já foram e nunca mais voltaram. (Júlia, família monoparental)

Ao longo de suas histórias, as crianças adotadas passaram por vivências de rupturas desde a família de origem. Desta forma, carregam 
consigo insegurança diante do outro, que pode desaparecer a qualquer momento. Para Silva et al. (2014), essas experiências fazem com que a criança empregue esforço psíquico demasiadamente grande na construção de novos vínculos. Trocar o abrigo, ambiente já conhecido, pela nova família, ambiente totalmente desconhecido, traz insegurança, uma vez que, na sua imaginação, a família pode ser um lugar perigoso.

Embora a maior parte das vivências anteriores das crianças tenha sido reconhecida pelos participantes como algo que trouxe consequências ruins para o presente, os entrevistados destacaram também a importância do passado na formação, demonstrando atenção aos aspectos bons de seus filhos e a importância de falar sobre $\mathrm{o}$ assunto.

Tem o lado que você tem que quebrar alguns conceitos, algumas histórias que nem sempre são boas, né, não trazem coisas boas, mas também procurar coisas boas nas histórias do passado que todos eles têm também, né. Porque pra chegar aonde chegaram e serem crianças como são é porque eles têm grandes valores aí, né. (Mario, família homoparental)

Não proíba o seu filho de falar do passado que é pra você entender o que aconteceu com ele e trabalhar isso no futuro com ele. ... Então essas experiências anteriores delas serve até pra entender a dinâmica delas hoje. (Vânia, família homoparental)

$\mathrm{Na}$ medida em que os pais compreendem as experiências trazidas, pode-se construir uma nova história que elabore o que do passado possa ter sido vivido como traumático e doloroso. Conforme assinalado por Silva et al. (2014), ouvir o passado possibilita que a criança reconte sua história e possa dar novos significados para ela. Ademais, de acordo com Schettini et al. (2006), a história da criança poderá dizer muito mais sobre a identidade que o filho adotivo irá assumir do que desse suposto passado.

A maioria destas crianças possui apegos e memórias importantes de convivência com a família biológica que, muitas vezes, são preservadas. A família adotiva terá que lidar com essas vivências e, ao receber seu filho, recebe também toda história vinda na bagagem. Os desafios de lidar com esse passado e escrever uma nova história se relacionam com as dificuldades nesse caminho de construção.

\section{Pedras no Caminho da Adoção Tardia}

As pedras no caminho da adoção tardia representam as principais dificuldades que os pais adotivos enfrentam no período inicial do convívio. Dentre estas, os entrevistados destacaram o comportamento agressivo com o qual tiveram que lidar no período de adaptação. Na adoção, muitas vezes, a família adotante idealiza que a criança será grata ao acolhimento e não causará maiores "problemas". Ao contrário, ela irá testar o ambiente de forma a obter a certeza de que será aceita mesmo com tudo de provocador e insatisfatório que possa ter (Levinzon, 2000) como evidenciado na fala de Fernanda:

As fases. Bem que me avisaram! Quando as crianças chegaram não foi um conto de fadas, isso é importante falar. Porque a gente acha que a criança vai tá muito grata, como muitas vezes acontece, mas nem sempre é assim. ... A B quando ela chegou ela testava muito. Ela tinha choros e birras... o vento mudou de posição, ela já estava chorando e eu achei que alguém ia bater na minha porta me acusando de maus tratos porque ela gritava, gritava... " $B$, por que você tá gritando?". "Não sei!" (Fernanda, família heteroparental)

De acordo com Weber (1998), o comportamento agressivo do filho adotado diz respeito ao medo da criança de ter a experiência de abandono repetida. Assim, ao invés de demonstrar amor, ela começa a testar esse novo ambiente e a demonstrar seu ódio. Para Winnicott (1947/2000b), muitas vezes, o que a criança procura é um ódio legítimo, e deve poder encontrá-lo, ao contrário, se sentirá incapaz de alcançar o amor. Nesta perspectiva, o autor menciona que as crianças vindas de lares desfeitos vivem em busca, mesmo que inconscientemente, dos pais. E é no momento em que encontram um lar que passam a testar o ambiente. Essa testagem faz parte do processo de vinculação e se configura como algo estruturante no processo de filiação e 
não deve ser entendido como algo destrutivo. A fala de Vânia exemplifica esse momento:

$O$ ruim da adoção tardia é justamente isso, você não consegue nutrir, você não consegue trabalhar amor com a criança, então tem que ter não é amor, é paciência, a chave pra adoção tardia, eu falo, é paciência, porque a criança não vai vim pra você "Mamãe eu te amo", "Mamãe você é linda", "Mamãe muito obrigada", não vai, ela vai te infernizar, ela vai bagunçar a sua estrutura emocional toda. (Vânia, família homoparental)

Para Levinzon (2000), o abandono por parte dos progenitores, muitas vezes, está ligado à fantasia de morte para a criança. Esse tipo de fantasia acaba gerando um mundo interno repleto de fantasias de destruição.

Um periodo que ele teve, assim, muitos episódios de agressividade, né, que o J, meu marido, às vezes ele tentava conter, às vezes, e ele dava mordidas, chutes, eu fiquei toda roxa também, porque no trato ele batia. . . . Mas era em algumas situações e assim, ele mesmo não se dava conta do que tava fazendo. Tanto que quando ele percebia que machucava, ele parava. (Ana, família heteroparental)

O mais novo, nós tivemos um problema que ele tinha explosões de raiva, então a gente tinha que conter ele e sempre que a gente colocava limite ele explodia. A gente teve que conter porque ele estava completamente violento, xingava todos os nomes que você possa imaginar gritando e dizendo que ia matar a gente que queria matar a gente, que queria voltar pro abrigo. (Lucas, família homoparental)

Conforme ilustrado nos relatos, a criança irá colocar para fora toda sua raiva em direção aos pais adotivos. Essa raiva deve ser acolhida e contida, demonstrando que eles podem sobreviver aos ataques. A criança precisará retomar a confiança no ambiente e reviver o que Winnicott (1963) chamou de ciclo benigno, formado a partir das repetidas vezes em que o bebê se percebe atacando de maneira voraz o corpo materno e experimenta o sentimento de culpa, não cons- ciente, pelas consequências de sua agressividade destrutiva. A partir disso, ele vai em busca de reparação, que deve ser acolhida pela mãe. Quando a mãe é capaz de acolher, por repetidas vezes, a destrutividade e o ato reparatório, num processo cíclico, o bebê se torna capaz de seguir sua construtividade, apropriando-se dos impulsos destrutivos de forma produtiva à vida.

O ciclo benigno deve ser retomado na adoção e os pais adotivos devem ser capazes de oferecer à criança a possibilidade de se apropriar de sua agressividade de forma construtiva. Essa vivência foi descrita por Vânia, ao contar como se deu a testagem do ambiente e a resolução desse movimento agressivo:

Com a $R$ foi tenso, porque ela não confiava na gente, então ela praticou tudo que ela podia fazer pra ser devolvida né, então foi... Foram seis meses de inferno, quando eu falo inferno, é inferno no último nível. . . Ai nesse dia eu tava dando banho nela, ela saiu correndo do banheiro e veio pra sala, toda molhada, com shampoo, gritando aqui, ai a Paula [esposa] levantou, pegou ela. Nesse dia, até esse dia, a Paula não tinha feito nada, deixou a $R$ fazer de um tudo. Ai ela segurou ela pelos braços, puxou, trouxe até o rosto dela e falou "Presta atenção, você pode botar fogo na casa..." aí foi falando o que ela podia fazer e o que ela não podia, "E você não vai ser devolvida, essa aqui é sua casa, sua família, aceita que dói menos". Soltou, nisso que ela soltou a menina, a menina parou, olhou pra mim, "Mãe, vamos lavar o cabelo?" (Vânia, família homoparental)

Outra dificuldade apontada pelos participantes foi a falta de segurança jurídica. Muitos dos processos de adoção que correm em juízo, atualmente, não contam com a destituição do poder familiar e isso apareceu nas falas da maioria dos entrevistados. Uma das prerrogativas do ECA é a restituição do convívio familiar, por isso, o processo de destituição familiar, muitas vezes, demora a ser concluído, até que se comprove que a família de origem não é capaz de retomar o cuidado da criança. Isso favorece que as crianças sejam postas para adoção com idade mais avan- 
çada, configurando a adoção tardia. Além disso, em alguns estados brasileiros, incluindo o Rio de Janeiro, a criança é colocada em família substituta, sob guarda provisória, antes mesmo da conclusão desse processo que acaba transcorrendo paralelamente ao processo de adoção. Isso acaba gerando insegurança para os pais adotivos que apresentam um sentimento de desamparo enorme. Isto terá implicação na formação do vínculo parento-filial.

Eu ainda posso algum dia receber uma cartinha ou um telefonema dizendo: "volta com teus filhos, eles vão morar com os pais". Incrivel isso! Que pais? A gente aqui todo relutante numa educação que não traumatize, que dê certo, né. A gente todo preocupado de como fazer, como agir e errando e acertando, mas preocupado sempre. . . E É um temor que a gente tem muito, muito mesmo. Eu não acho que vai acontecer, mas... até tá lá o nominho na certidão ... a gente fica com o pé atrás. (Fernanda, família heteroparental)

A maioria dos entrevistados mencionou a dificuldade no estabelecimento de regras:

Dificuldades no caso dele foram, assim, ele não tinha, até hoje ele não tem ainda, costume com regras, disciplinas . . . foi essa dificuldade, a dificuldade foi ele acostumar, acho que é normal, ele se reeducar com novas disciplinas, novos horários, o colégio, enfim, com uma nova vida, né gente! (André, família monoparental)

Costa e Rossetti-Ferreira (2007) destacam que a principal dificuldade do pai adotivo em desenvolver sua parentalidade com crianças maiores está na contestação das regras e do seu lugar de autoridade. A criança maior já chega com a capacidade de se contrapor e argumentar junto aos pais, o que reflete uma das particularidades desse tipo de adoção e pode ser notado em algumas falas.

Outra dificuldade mencionada pelos participantes foi a questão do atraso escolar. Na maioria dos discursos, emergiu o desafio em lidar com o analfabetismo dos filhos.

E a outra era a questão da educação mesmo, da educação formal. Ela não sabia se- parar sílabas e ela tava no quarto ano, na época. Então a gente vai levar ela pra uma escola particular e como é que ela vai ficar? (Mario, família homoparental)

Outro aspecto mencionado nas falas dos pais foi a ambiguidade entre amadurecimento precoce e regressão infantil. Estas crianças tiveram que assumir um lugar de independência no autocuidado, mesmo que de forma precária, muito cedo (Altoé \& Silva, 2013). Por isso, observa-se nas crianças que vivem em instituições de acolhimento, de um modo geral, uma pseudo-autonomia. Contudo, ao sentirem-se seguros numa família que ofereça cuidado, nota-se certa regressão, no sentido de assumirem posturas infantis, como forma de permitir o cuidado.

Quando chegou, ela era uma criança completamente independente pra uma criança de dois anos e meio, eu só não digo que era cem por cento porque ela ainda usava fralda. . . Ai depois teve a regressão né, me ajuda, não sei fazer, não sei o que, nada fazia mais sozinha. . . Quis mamar no meu peito, eu falei assim: "mas não sai leite! [risos] nem você tem mais idade pra isso". "Ah, mas eu quero!". Não adianta, eu deixei, aí falou: "não sai" aí eu: "pois é, não sai". Falei assim, "você quer beber seu leite no copinho, na posição?" "Ah, quero!" Aí botei ela deitadinha, como se realmente tivesse sendo amamentada, mas no copinho, que nem na mamadeira ela bebia mais. (Julia, família monoparental)

Todas essas dificuldades mencionadas pelos entrevistados foram acolhidas de forma singular, favorecendo a construção do sentimento de segurança e fortalecendo o vínculo na medida em que a criança percebia poder confiar nesse novo ambiente cuidador. Todavia, para uma das mães entrevistadas, lidar com a testagem demasiadamente intensa da filha estava sendo, até o momento da entrevista, um desafio muito complexo, mesmo depois de seis anos da adoção. Nota-se, na sua fala, a fragilização desse vínculo:

Então o amor pra mim... eu sei lá, algo assim que eu não sei mensurar. Eu só sei que desde o momento que ela entrou na minha vida, ela se tornou minha filha, né. É lógico 
que assim, o meu amor foi se desgastando . .. Então hoje em dia, eu penso assim, será que o que eu sinto hoje em dia é desamor? Entendeu? Hoje, com essas coisas que eu tô vivendo, será que é um desamor? Será que não era nada daquilo e eu achei que fosse? Será que era compaixão? Será? O que será que era, né? Então assim, hoje eu sinto um pesar muito grande. É como se fosse assim, alguém que me deu uma decepção muito grande e assim, que eu queria tirar do meu peito, mas eu não posso tirar do meu peito. (Laura, família monoparental)

\section{Adoção Mútua}

A ideia de construção mútua foi expressa nas falas dos sujeitos demonstrando como os desejos, vivências e vontades próprias das crianças influenciam diretamente na construção do vínculo parento-filial.

Eu acho que encontrei meu filho mesmo. E talvez... eu até te falo, foi até melhor do que se fosse um filho gerado, porque esse eu tive toda chance de, entre aspas, escolher e ele me escolher e a gente tá construindo juntos, uma vida juntos, com desafios, com problemas, mas com muito carinho, com muito amor. (André, família monoparental)

$\mathrm{Na}$ adoção tardia, já existe uso da linguagem e uma história pregressa repleta de experiências que fazem com que a criança se apresente não mais como um ser incompleto e, por isso, exige outros modos de vinculação afetiva. Segundo Costa e Rossetti-Ferreira (2007), nessas adoções, as crianças são capazes de negociar a afetividade e a construção do amor filial, posicionando-se na relação de forma mais ativa que um bebê. Tal proposição ficou evidenciada nas falas de Vânia e Claudia:

Aí ela fez uma pergunta que me marcou, uma criança de 5 anos e 6 meses fazendo esse tipo de pergunta, ela perguntou assim "É para sempre? Todo sempre?" eu nunca tinha ouvido dessa forma o tal do 'para sempre' junto com 'todo sempre' falei, "gente, que pergunta é essa?" né, aí aquilo, parei, falei: "O que que eu respondo?" (Vânia)
Mas o que me emocionou no primeiro momento foi a minha filha porque ela é toda meiguinha, toda sedutora e ela chegou e "você quer ser minha mãe?" gente! Muito forte uma menina de oito anos falar isso pra você. Ai eu falei: "quero!" Aí ela começou a me chamar de mamãe, naquele momento. (Claudia, família heteroparental)

Alguns dos entrevistados assinalaram a importância de aprender junto com a criança a se tornarem pais:

Então tá sendo assim, um periodo de adoção tanto da gente com eles como deles com a gente. A gente também tá aprendendo o que é ser pai . . Eles mesmos, da mesma forma que a gente localiza eles, olha, do que eles têm que fazer, eles também localizam a gente. ... Eles, de certa forma, sabem colocar a gente no nosso lugar porque a gente também tem que ser colocado no lugar de pais, né. Da mesma forma que a gente vai colocar eles no lugar de filho. (Fernanda, família heteroparental)

Alguns pais mencionaram a ilusão inerente à tentativa de "colocar a criança no seu jeito" e a necessidade de respeitar o filho e sua história. Nas falas a seguir, Vânia compara a experiência com $\mathrm{M}$, adotada aos seis meses, com a experiência com as outras duas filhas, adotadas com cinco e com 12 anos. André cita o conflito entre gostos como uma especificidade da adoção tardia:

Conforme a gente foi vivendo, foi uma aprendendo com a outra. Igual, falam assim: "ah, não quero filho grande porque não vou botar do meu jeito". Não existe o meu jeito. Eu descobri isso que não existe o meu jeito. Porque se fosse assim, a M seria do meu jeito porque ela convive comigo desde que nasceu. . . Então não existe esse botar do meu jeito. Cada um tem o seu jeito, o que a gente aprende é a respeitar o espaço do outro ou podar algumas coisas. (Vânia, família homoparental)

Essa é a diferença da adoção tardia, porque quando você pega de pequenininho, você doutrina naquilo que você gosta e aos pouquinhos ela vai vendo que ela gosta. Nesse caso não, ele já vem com uma bagagem 
do que ele gosta, eu preciso respeitar isso ... Um fato importante e interessante, ele ama filme de terror, ama! E eu odeio filme de terror e proibi ele de ver. Ele ia lá e eu desligava, desligava, desligava. Ai um dia ele falou assim: "isso não é justo! Quando o senhor me conheceu eu já gostava de filme de terror, então o senhor não quer ver, vai pra o seu quarto e eu vejo na sala. Então eu posso ver, posso?" Então eu parei e falei "ele tá hiper correto, é claro que pode ver". (André, família monoparental)

Nesse processo mútuo, transpassado por vivências e histórias, torna-se inegável que essa bagagem tenha seu efeito na construção do vínculo parento-filial. Conforme assinalado por Schettini et al. (2006), compreender o passado que a criança traz, sem negá-lo, pode favorecer a construção de uma nova história capaz de reparar o que antes possa ter se apresentado como faltoso ou até mesmo negligente. De acordo com Dias, Silva e Fonseca (2008), diante das dificuldades, a lucidez, o amor e o empreendimento dos pais no cuidado da criança potencializa a convivência.

\section{Considerações Finais}

Os resultados da pesquisa apontam para a importância da atenção prestada ao histórico de vivências da criança. Por se tratar de adoção de crianças maiores, elas já irão chegar à nova família com uma bagagem de experiências. Para alguns pais, o medo dos costumes trazidos pela criança, ainda é bastante presente. Contudo, pôde-se perceber, nas falas dos entrevistados, que esses medos eram baseados em crenças anteriores à entrada no processo de adoção. Para a maioria, a participação nos Grupos de Apoio à Adoção, as leituras sobre o tema e as palestras com profissionais ajudaram a desmistificar as fantasias sobre as interferências no processo de adoção tardia.

Outro aspecto importante mencionado pelos participantes foi a adaptação à rotina, também associada ao histórico de descuido. De acordo com a fala da maioria dos entrevistados, as negligências sofridas na família de origem e/ou na passagem pelas instituições de acolhimento que, muitas vezes, não possuem infraestrutura que favoreça o cuidado, colaboraram para a dificuldade na adaptação da rotina familiar.

Ademais, os pais entrevistados apontam para uma lacuna importante no conhecimento das informações essenciais sobre o início do desenvolvimento. Quanto a isso, seria interessante que fossem desenvolvidos projetos que zelassem pela história de saúde da criança desde o nascimento para que a família adotiva tivesse acesso a informações como, por exemplo, as condições de parto, doenças comuns na infância, avanços no desenvolvimento, e outras.

Dentre as principais dificuldades durante a adaptação, foram mencionadas a imposição de regras, o comportamento agressivo, falta de segurança jurídica, atraso escolar, regressão infantil e adaptação à rotina familiar. Todos esses desafios apareceram para os pais entrevistados e a maneira como cada um acolheu e lidou com cada dificuldade foi de importância fundamental para garantir o fortalecimento do vínculo parento-filial.

Conhecer o histórico da criança pôde auxiliar as famílias na adaptação quanto às necessidades principais e na ressignificação de possíveis falhas do passado muitas vezes doloroso e marcado por rupturas e abandonos. O respeito à história pregressa foi essencial para a construção e manutenção do vínculo parento-filial.

Por se tratar de adoção de criança maior, sobretudo, entende-se que essa nova construção se dará como uma via de mão dupla, numa adoção mútua capaz de ressignificar o passado, sem precisar apagá-lo, antes disso, construindo a possibilidade de uma nova história integradora. Desta forma, torna-se possível a construção de um futuro capaz de reparar o que possa ter havido de ruim e legitimar o que possa ter ficado de bom.

O presente estudo foi realizado com um grupo reduzido de participantes, o que não permite a generalização das conclusões aqui apresentadas. Ressalta-se a necessidade de desenvolver pesquisas que abordem fatores que possam interferir na construção do vínculo parento-filial nas adoções tardias, contribuindo com conhecimentos para promoção de saúde emocional das famílias. 


\section{Referências}

Altoé, S., \& Silva, M. M. (2013). Características de uma clínica psicanalítica com crianças e adolescentes em situação de vulnerabilidade social. Estilos da Clínica (São Paulo), 18(1), 125-141. Recuperado em http://pepsic.bvsalud.org/pdf/ estic/v18n1/a08v18n1.pdf

Amim, I. D., \& Menandro, P. R. M. (2007). Preferências por características do futuro filho adotivo manifestadas por pretendentes à adoção. Interação em Psicologia, 11(2), 241-252. doi:http:// dx.doi.org/10.5380/psi.v11i2.7653

Baptista, J., Soares, I., \& Henriques, M. (2013). Recuperação desenvolvimental após a adoção: Características da criança e da família adotiva. Psicologia: Reflexão e Crítica, 26(2), 396-404. Recuperado em http://hdl.handle. net/10216/70543

Bardin, L. (2011). Análise de conteúdo. Lisboa: Edições 70 .

Böing, E., \& Crepaldi, M. A. (2004). Os efeitos do abandono para desenvolvimento psicológico de bebês e a maternagem como fator de proteção. Estudos de Psicologia (Campinas), 21(3), 211-226. doi:https://dx.doi.org/10.1590/S0103$-166 \times 2004000300006$

Cadastro Nacional de Adoção. (2016). Relatórios estatísticos. Brasília, DF: Conselho Nacional de Justiça. Recuperado em http://www.cnj.jus.br/ cnanovo/pages/publico/index.jsf

Costa, N. R., \& Rossetti-Ferreira, M. C. (2007). Tornar-se pai e mãe em um processo de adoção tardia. Psicologia: Reflexão e Crítica, 20(3), 425434. Recuperado em http://www.scielo.br/pdf/ $\mathrm{prc} / \mathrm{v} 20 \mathrm{n} 3 / \mathrm{a} 10 \mathrm{v} 20 \mathrm{n} 3 . \mathrm{pdf}$

Dias, C. M. S. B., Silva, R. V. B., \& Fonseca, C. M. S. M. S. (2008). Adoção de crianças maiores na perspectiva dos pais adotivos. Contextos Clínicos, 1(1), 28-35. Recuperado em http:// pepsic.bvsalud.org/scielo.php? script $=$ sci arttext\&pid=S1983-34822008000100004\&lng= $\mathrm{pt \& t} \operatorname{lng}=\mathrm{pt}$

Ebrahim, S. G. (2001). Adoção tardia: Altruísmo, maturidade e estabilidade emocional. Psicologia, Reflexão e Crítica, 14(1), 73-80. Recuperado em http://www.scielo.br/pdf/prc/v14n1/5208

Fernández, M., \& Fuentes, M, J. (2004) Como valoran las familias la adopción de niños mayores: implicaciones para la actuación de los técnicos. Bienestar y Protección Infantil, 2(3), 97-112. Recuperado em http://www. bienestaryproteccioninfantil.es/imagenes/ tablaContenidos03SubSec/Revista_Vol3 Num2_Completo.pdf\#page $=93$

Ghirardi, M. L. A. M. (2009). A devolução de crianças adotadas: Ruptura do laço familiar. Pediatria Moderna, 45(2), 66-70. Recuperado em http://www.moreirajr.com.br/revistas.asp?id materia $=3988 \&$ fase $=$ imprime

Gomes, K. (2006). A adoção à luz da teoria winnicottiana. Winnicott e-prints, 1(2), 51-68. Recuperado em http://pepsic.bvsalud.org/scielo. php?script $=$ sci_arttext\&pid=S1679-432X20060 00200005\&lng=pt\&tlng=en

Ladvocat, C. (2001). Mitos e segredos sobre a origem da criança na família adotiva (Dissertação de mestrado, Departamento de Psicologia, Pontifícia Universidade Católica do Rio de Janeiro, RJ, Brasil).

Lei $\mathrm{n}^{\circ}$ 12.010, de 3 de agosto de 2009. (2009, 3 ago.). Dispõe sobre adoção; altera as Leis nos 8.069, de 13 de julho de 1990 - Estatuto da Criança e do Adolescente. Recuperado em http://www. planalto.gov.br/ccivil_03/_Ato2007-2010/2009/ Lei/L12010.htm

Lei $n^{\circ} 8.069$, de 13 de julho de 1990. (1990, 13 jul.). Dispõe o Estatuto da Criança e do Adolescente e dá outras providências. Brasília, DF: Casa Civil, Subchefia para assuntos jurídicos. Recuperado em http://www.planalto.gov.br/ccivil_03/leis/ L8069.htm

Levinzon, G. K. (2000) A criança adotiva na psicoterapia psicanalítica (2. ed.) São Paulo, SP: Escuta.

Levy, L., Pinho, P. G. R., \& Faria, M. M. (2009). “Família é muito sofrimento": Um estudo de casos de "devolução" de crianças. Psico, 40(1), 58-63. Recuperado em https://dialnet.unirioja.es/servlet $/$ articulo?codigo $=5161484$

Londen, W. M., Juffer, F., \& IJzendoorn, M. H. (2007). Attachment, cognitive and motor development in adopted children: Short-term outcomes after international adoption. Journal of Pediatric Psychology, 32(10), 1249-1258. doi:10.1093/jpepsy/jsm062

Luz, A. F., Gelain, D., \& Amaral, L. M. (2014). Vivênciasdas famíliasnaadoçãotardia.RevistadePsicologia da IMED, 6(1), 52-57. doi:10.18256/21755027 / p s i c o-i m e d.v 6 n 1 p $52-57$ 
Morelli, A. B., Scorsolini-Comin, F., \& Santeiro, T. V. (2015). O " lugar" do filho adotivo na dinâmica parental: Revisão integrativa de literatura. Psicologia Clínica, 27(1), 175-194. doi:http:// dx.doi.org/10.1590/0103-56652015000100010

Otuka, L. K, Scorsolini-Comin, F., \& Santos, M. A. (2012). Adoção suficientemente boa: Experiência de um casal com filhos biológicos. Psicologia: Teoria e Pesquisa, 28(1), 55-63. doi:http:// dx.doi.org/10.1590/S0102-37722012000100007

Peiter, C. (2011). Adoção,vínculos e rupturas: Do abrigo à família adotiva. São Paulo, SP: Zagodoni.

Schettini, S. S. M., Amazonas, M. C. L. A., \& Dias, C. M. S. B. (2006). Famílias adotivas: Identidade e diferença. Psicologia em Estudo, 11(2), 285-293. doi:http://dx.doi.org/10.1590/S141373722006000200007

Silva, M. L., \& Arpini, D. M. (2013). A Nova Lei Nacional de Adoção: Desafios para a reinserção familiar. Psicologia em Estudo, 18(1), 125-135. doi:http://dx.doi.org/10.1590/S141373722013000100013

Silva, M. P. O., Guimarães, F. L., \& Pereira, S. K. R. (2014). Caminhos da Adoção. In C. Ladvocat (Ed.), Guia da adoção: No jurídico, no social, no psicológico e na família. São Paulo, SP: Roca.

Vargas, M. M. (2013). Adoção tardia: Da família sonhada à família possível (2. ed.). São Paulo, SP: Casa do Psicólogo. (Original publicado em 1998)
Weber, L. N. D. (1998). Famílias adotivas e mitos sobre o laço de sangue. Jornal Contato CRP, 8(79). Recuperado em http://www.nac.ufpr.br/ wp-content/uploads/2016/07/1996_Familias adotivas_e_mitos_sob_relacoes_de_sangue.pdf

Winnicott, D. W. (1963). O desenvolvimento da capacidade de se preocupar. In D. W. Winnicott, O ambiente e os processos de maturação. Porto Alegre, RS: Artes Médicas.

Winnicott, D. W. (2000a). Desenvolvimento emocional primitivo. In D. W. Winnicott, Da Pediatria à Psicanálise: Obras escolhidas (Cap. 12, pp. 218-232). Rio de Janeiro, RJ: Imago. (Original publicado em 1945)

Winnicott, D. W. (2000b). O ódio na contratransferência. In D. W. Winnicott, Da Pediatria à Psicanálise: Obras escolhidas. Rio de Janeiro, RJ: Imago. (Original publicado em 1947)

Zornig, S. A. J., \& Levy, L. (2006). Uma criança em busca de uma janela: Função materna e trauma. Estilos da Clínica, 11(20), 28-37. Recuperado em http://pepsic.bvsalud.org/scielo.php?script=sci arttext\&pid $=$ S1415-71282006000100003\&lng $=$ pt\&tlng=pt

(C) O(s) autor(es), 2018. Acesso aberto. Este artigo está distribuído nos termos da Licença Internacional Creative Commons Atribuição 4.0 (http://creativecommons.org/licenses/by/4.0/), que permite o uso, distribuição e reprodução sem restrições em qualquer meio, desde que você dê crédito apropriado ao(s) autor(es) original(ais) e à fonte, fornecer um link para a licença Creative Commons e indicar se as alterações foram feitas. 